\title{
Attitude and knowledge of medical students toward donation after circulatory death
}

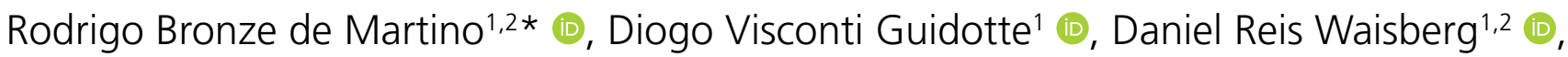 \\ Alexandre Guerra dos Santos ${ }^{1}(1)$, Alex Jones Flores Cassenote ${ }^{1,2}$ (1), \\ Rubens Macedo Arantes ${ }^{1,2}$ (D), Luciana Bertocco Haddad ${ }^{1,2}$ (D), \\ Flavio Henrique Galvão ${ }^{1,2}$ (1), Luiz Augusto Carneiro-D'Albuquerque ${ }^{1,2}$
}

\begin{abstract}
SUMMARY
OBJECTIVE: A survey among medical students in a Brazilian public university was performed to investigate the acceptance of organ donation in Brazil, particularly donation after circulatory death (DCD).

METHODS: A questionnaire including 26 objectives and Likert scale questions was validated and sent to all medical students of our institution. The answers were analyzed considering the whole set of individuals as well as by dividing the medical students into two groups: less graduated students and more graduated students.

RESULTS: From 1050 students, 103 spontaneous answers (9.8\%) were retrieved after 3 weeks. A total of $89.3 \%$ agreed totally with deceased donor organ donation and $8.7 \%$ agreed partially. However, only $50.5 \%$ of the students agreed totally and $31.1 \%$ agreed partially to living donation. Students revealed that $82.6 \%$ know the concept of brain death. On the other hand, $71.8 \%$ of them declared not knowing the concept of planned withdrawal of life-sustaining therapy, mainly cardiorespiratory support. A total of $85.4 \%$ of students agreed totally with donation after brain death and $11.7 \%$ agreed partially. However, when questioned about donation in awaiting circulatory death after a planned withdrawal of life-sustaining therapy, only $18.4 \%$ agreed totally and $32 \%$ agreed partially. Both groups of less and more graduated students showed similar results.

CONCLUSIONS: Our study found a clear lack of information and consequently in acceptance of DCD. Education in the field of end-oflife management may improve not only the acceptance of DCD donation but also the whole understanding of planned withdrawal of life-sustaining therapy.

KEYWORDS: Death, sudden, cardiac. Health knowledge, attitudes, practice. Students, medical. Surveys and questionnaires. Organ transplantation.
\end{abstract}

\section{INTRODUCTION}

In the 90s, the Maastricht's group established the four categories for DCD donors, and it had a great impulse'. Nowadays, this practice is legitimate in the United States, many European countries, Canada, Australia, Japan, China, but still not accepted in Brazil ${ }^{2}$.
The current organ shortage for transplantation and the increased graft demand for patients in waiting list prospect DCD as an effective source of grafts, expanding the potential donor pool. Over the last decades, DCD donors have been responsible for a significant increase in numbers of deceased

\footnotetext{
${ }^{1}$ Hospital das Clinicas da Faculdade de Medicina da Universidade de São Paulo, Divisão de Transplante de Órgãos Abdominais e Fígado, Departamento de Gastroenterologia - São Paulo (SP), Brazil.

${ }^{2}$ Faculdade de Medicina da Universidade de São Paulo, Laboratório de Investigação Médica-37 (LIM-37) - São Paulo (SP), Brazil.

*Corresponding author: rb.demartino@gmail.com

Conflicts of interest: the authors declare there is no conflicts of interest. Funding: Fundação de Amparo à Pesquisa do Estado de São Paulo - process number 17/24771-7.
}

Received on January 27, 2021. Accepted on February 01, 2021. 
organ donors, while donors after brain death (DBD) has remained broadly stable, particularly in some countries such as the United Kingdom ${ }^{3,4}$.

In Brazil, despite the advances in last decade, the rate of effective donation was only 17.0 per million population in $2018^{5}$; therefore, far to supply the needs of those in the waiting list. These data clearly show the importance of discussing the acceptance of DCD in the Brazil.

In general, the Brazilian society is quite conservative, and the lack of appropriate education remains an ordeal especially in the poorer areas of the country. These aspects surely impair the debate about DCD in our context. However, medical students supposedly represent a well-educated part of the society.

The attitude of medical students toward DCD has not been investigated in Brazil so far. To address this issue, we conducted a survey among medical students from our institution in order to better understand the acceptance of DCD along the graduation course in medicine.

\section{METHODS}

In an analytical-descriptive study, medical students from the first to the sixth year from the Faculty of Medicine of the University of Sáo Paulo (FMUSP) voluntarily responded to an anonymously questionnaire designed to determine their knowledge and opinion on organ donation, particularly on DCD. This study was approved by the local Ethical Committee (CAPPESQ 3.291.655).

The questionnaire was validated by six referees: two senior physicians who worked in a liver transplant program for more than 10 years, two medical students, one statistician, and one chief nurse coordinator from our liver transplantation program. The enquiry included 26 objectives and Likert scale questions, allowing the student to choose from the following alternatives: "agree partially," "agree totally," "disagree partially," "disagree totally," or to be "indifferent" to the situation proposed by the question. The questionnaire was sent by e-mail to all students from the FMUSP.

The answers to the questionnaire were analyzed considering the whole set of individuals as well as by dividing the medical students into two groups: less graduated students (from first to third graduation year) and more graduated students (from fourth to sixth graduation year), who have been more exposed to clinical practice. The students' sex, self-determined religion, and origin of the state were also evaluated.

The Mann-Whitney $U$ test was used to compare the answers between the two groups, and the chi-square test was used to analyze the answers among the different religious beliefs. The statistical significance was set at 0.05 . All statistical analyses were performed using the R software with packages "stats" and "rstatix" (https://www.r-project.org/).

\section{RESULTS}

We retrieved 103 spontaneous answers after 3 weeks. Considering that the total number of students of the school is 1050 , we observed a $9.8 \%$ of spontaneous answers to thequestionnaire. The higher number of responses was in the third year $(27.2 \%)$, followed by the second (22.3\%), first (19.4\%), fourth (13.6\%), fifth $(9.7 \%)$ and only $7.8 \%$ from the sixth year of the medical school.

A total of $50.5 \%$ of the enquire was answered by women and $49.5 \%$ by men. The majority of the responses were from students from São Paulo state (82.5\%). Regarding religion, $31.1 \%$ of the students classified themselves as agnostic, $23.3 \%$ as atheist, $19.4 \%$ as catholic, $7.8 \%$ as Kardecist spiritists, $4.9 \%$ as having no religion, $3.9 \%$ as protestant, and $8.7 \%$ as others.

Concerning student's statement regarding organ donation and transplantation, $78.6 \%$ answered that it would be an issue for medical graduation program and $81.6 \%$ for postgraduation course. Moreover, $36.9 \%$ have evaluated their knowledge about this issue as regular, 35\% as inadequate, and only $18.4 \%$ as adequate. In fact, only $44.7 \%$ declared to have studied this subject during medical school.

The collected results showed that students are steadily aware about donor/recipient imbalance in organ transplantation waiting list, as $88.4 \%$ agreed completely or partially with the affirmation of not having enough donors for transplantation in Brazil. At the same time, 95.2\% of the students seem to trust in transplantation as a life-saving procedure, as when they agreed in undergoing this treatment if necessary. In fact, $89.3 \%$ agreed totally with deceased donor organ recovery and $8.7 \%$ agreed partially. When confronted to a living donation, $50.5 \%$ of the students agreed totally and $31.1 \%$ agreed partially. Despite this decrease in agreement, $73.8 \%$ of the students agreed totally to donate part of their livers for a loved one and $19.4 \%$ agreed partially.

On the one hand, students revealed that $82.6 \%$ have some knowledge on the concept of brain death; however, only $31.1 \%$ answered, and they completely comprehended this issue. On the other hand, $71.8 \%$ of them declared not knowing the concept of planned withdrawal of life-sustaining therapy, mainly cardiorespiratory support. When asked about the concept of unsuccessful resuscitation after cardiac arrest, 68.9\% responded to fully or partially comprehend. 
When the enquire targeted the acceptance of donation after brain death, $85.4 \%$ of the students agreed totally and $11.7 \%$ agreed partially. However, when questioned about donation in awaiting cardiac or circulatory death after a planned withdrawal of life-sustaining therapy, only $18.4 \%$ agreed totally and $32 \%$ agreed partially (Table 1 ). When the question was about acceptance of donation in case of unsuccessful resuscitation after cardiac arrest, 39.8\% agreed totally and 27.2\% agreed partially (Table 1), even though $95.1 \%$ agreed in being an organ donor in case of this type of death.

Concerning the best donation criteria, $57.3 \%$ of the students preferred presumed donation and $23.3 \%$ chose consented donation. A total of $76.7 \%$ agreed totally for donation in case of a family member having a brain death diagnosis and $16.5 \%$ agreed partially. However, when asked about authorization for donation in case of a family member having an unsuccessful resuscitation after cardiac arrest, $50.5 \%$ students agreed totally and $27.2 \%$ agreed partially.

Table 1. Students demonstrated greater acceptance of organ donation after brain death but less acceptance of donation after circulatory death.

\begin{tabular}{|c|c|c|c|c|}
\hline & \multirow{2}{*}{$n$} & \multirow{2}{*}{$\%$} & \multicolumn{2}{|c|}{$95 \% \mathrm{Cl}$} \\
\hline & & & Lower & Upper \\
\hline \multicolumn{5}{|c|}{$\begin{array}{l}\text { Do you agree with organ donation in cases of } \\
\text { brain death? }\end{array}$} \\
\hline Indifferent & 3 & 2.9 & 0.0 & 9.5 \\
\hline Partially agree & 12 & 11.7 & 5.8 & 18.3 \\
\hline Totally agree & 88 & 85.4 & 79.6 & 92.0 \\
\hline \multicolumn{5}{|c|}{$\begin{array}{l}\text { Do you agree with organ donation after cardiac } \\
\text { arrest, when the patient has an unfavorable } \\
\text { neurological prognosis, but is not yet diagnosed } \\
\text { with brain death? }\end{array}$} \\
\hline Totally disagree & 8 & 7.8 & 0.0 & 17.6 \\
\hline Partially disagree & 15 & 14.6 & 4.9 & 24.4 \\
\hline Indifferent & 28 & 27.2 & 17.5 & 37.0 \\
\hline Partially agree & 33 & 32.0 & 22.3 & 41.9 \\
\hline Totally agree & 19 & 18.4 & 8.7 & 28.3 \\
\hline \multicolumn{5}{|c|}{$\begin{array}{l}\text { Do you agree with organ donation in cases of } \\
\text { cardiac arrest in emergency care which did not } \\
\text { respond to resuscitation maneuvers? }\end{array}$} \\
\hline Totally disagree & 5 & 4.9 & 0.0 & 15.1 \\
\hline Partially disagree & 8 & 7.8 & 0.0 & 18.0 \\
\hline Indifferent & 21 & 20.4 & 10.7 & 30.6 \\
\hline Partially agree & 28 & 27.2 & 17.5 & 37.4 \\
\hline Totally agree & 41 & 39.8 & 30.1 & 50.0 \\
\hline
\end{tabular}

Cl: confidence interval.
We also investigated whether self-determined religion could influence the students' answers regarding acceptance of donation after brain death, in DCD Maastricht's groups II and III. In none of these situations, religion had no impact on their answers ( $\mathrm{p}=0.343, \mathrm{p}=0.741$, and $\mathrm{p}=0.695$, respectively).

Finally, we investigated if the acceptance of organ donation was different between the two groups of students according to their graduation year. We could not find any influence of the students' training process in the acceptance of organ donation, particularly regarding DCD donation (Table 2).

\section{DISCUSSION}

In order to understand the view and the acceptance of organ donation in Brazil, particularly DCD donation, this survey was conducted in a selected portion of our society: students from a medical school. Even though we have retrieved only $9.8 \%$ of the enquiries sent to the students, we obtained enough answers to study their view. Despite the use of social media, the current adherence index was lower than a previous survey investigating the attitude about organ transplantation of medical students from this same faculty $(33.04 \%)^{6}$.

Our results have showed that medical students are steadily aware about the insufficient rate of donors for patients on waiting lists for organ transplantation in their countries, and they clearly responded in favor to donation after brain death. However, we could observe some reluctance toward living donation. Chen et al., in an investigation with university students in China, observed higher willingness to donate a living kidney to a relative $(94 \%)$ than to donate after death $(61.3 \%)^{7}$. In contrast, $89.3 \%$ of our students totally agreed with deceased donor organ donation and only $50.5 \%$ with living donation. However, $73.8 \%$ of the students totally agreed to donate part of their livers for someone next to them. Comparing these two different results, we can clearly observe the cultural differences of these two societies. Despite the well-educated individuals investigated in both enquires, these conflicting results suggest that East countries have difficult in accepting deceased donation, while West countries struggle to proceed with living donation.

The perspectives of medical students and nurses toward transplantation and donation have been investigated earlier ${ }^{7-10}$. Ríos et al., studying the acceptance of living liver donation among medical students in Spain, could not find any influence of the religion of the students ${ }^{9}$, similar to the results of this study. On the other hand, Dutra et al. found a higher willing to donate organs among spiritual students than in Catholics and Protestants ${ }^{8}$. Xie et al. found an unfavorable view of nurses in China regarding this issue and advocated for a better training for this important group of professionals ${ }^{10}$. The view of patients 
Table 2. Students were divided between the first 3 and the last 3 years of medical course.

\begin{tabular}{|c|c|c|c|c|c|}
\hline & \multicolumn{2}{|c|}{ First 3 years of medical school } & \multicolumn{2}{|c|}{ Last 3 years of medical school } & \multirow{2}{*}{ p-value* } \\
\hline & $\mathrm{n}$ & $95 \% \mathrm{Cl}$ & $\mathrm{n}$ & $95 \% \mathrm{Cl}$ & \\
\hline \multicolumn{6}{|c|}{ Do you agree with organ donation in cases of brain death? } \\
\hline Indifferent & - & - & 3 & $4.23(0-13.59)$ & \multirow{3}{*}{0.1044} \\
\hline Partially agree & 2 & $6.00(0.00-13.00)$ & 10 & $14.08(7.04-23.45)$ & \\
\hline Totally agree & 30 & $94.00(88.00-100.00)$ & 58 & $81.69(74.65-91.05)$ & \\
\hline \multicolumn{6}{|c|}{$\begin{array}{l}\text { Do you agree with organ donation after cardiac arrest, when the patient has an unfavorable neurological } \\
\text { prognosis, but is not yet diagnosed with brain death? }\end{array}$} \\
\hline Totally disagree & 4 & $13.00(0.00-31.00)$ & 4 & $5.63(0.00-17.89)$ & \multirow{5}{*}{0.5709} \\
\hline Partially disagree & 2 & $6.00(0.00-25.00)$ & 13 & $18.31(7.04-30.57)$ & \\
\hline Indifferent & 11 & $34.00(19.00-53.00)$ & 17 & $23.94(12.68-36.20)$ & \\
\hline Partially agree & 11 & $34.00(19.00-53.00)$ & 22 & $30.99(19.72-43.24)$ & \\
\hline Totally agree & 4 & 13.00(0.00-31.00) & 15 & 21.13(9.86-33.38) & \\
\hline \multicolumn{6}{|c|}{$\begin{array}{l}\text { Do you agree with organ donation in cases of cardiac arrest in emergency care which did not respond to } \\
\text { resuscitation maneuvers? }\end{array}$} \\
\hline Totally disagree & 2 & $6.00(0.00-25.00)$ & 3 & $4.23(0.00-17.12)$ & \multirow{5}{*}{0.9344} \\
\hline Partially disagree & 5 & $16.00(0.00-34.00)$ & 3 & $4.23(0.00-17.12)$ & \\
\hline Indifferent & 3 & $9.00(0.00-28.00)$ & 18 & $25.35(14.08-38.25)$ & \\
\hline Partially agree & 8 & $25.00(9.00-43.00)$ & 20 & $28.17(16.90-41.07)$ & \\
\hline Totally agree & 14 & $44.00(28.00-62.00)$ & 27 & $38.03(26.76-50.93)$ & \\
\hline
\end{tabular}

Both groups presented similar responses, showing no significant influence of the level of medical training at the acceptance of organ donation. $\mathrm{Cl}$ : confidence interval.

*p-value calculated by the Mann-Whitney U method.

has also been investigated ${ }^{11}$, showing the lack of education as a major problem and advocated for better public information to improve organ donation acceptance. In this study, we found a decent level of knowledge of the concept of brain death among students (82.6\%), which translated into a high acceptance of donation with brain death. However, the knowledge and acceptance of DCD donation was lower.

Regarding DCD donation, which is the main goal of this study, we already expected that it would be a difficult discussion in our society. For example, despite still a matter of debate in developed countries, end-of-life interventions are much well accepted in Europe ${ }^{12}$. Different from other countries, removing life support in terminal patients in Brazil is not welcome in general. In our results, $71.8 \%$ of the students do not know the concept of planned withdrawal of life-sustaining therapy, mainly cardiorespiratory support. They are quite used to not fully invest in patients with critical prognosis; however, planning withdraw of life-sustaining therapy is still highly controversial in Brazil, and this was revealed in this study.
This controversy clearly impacted the student's responses regarding DCD donation. While $85.4 \%$ answered to completely agree with brain death donation, only $18.4 \%$ agreed totally and 32\% agreed partially with DCD Maastricht category III, and $39.8 \%$ agreed totally and $27.2 \%$ agreed partially with DCD Maastricht category II. Indeed, this was again revealed when the students were asked about consenting donation in case of a loved one's brain death, and $76.7 \%$ were totally in agreement; whereas, when consenting donation in case of a family member having an unsuccessful resuscitation after cardiac arrest, only $50.5 \%$ of the students agreed totally. Interestingly, these points-of-view do not change during the course of medical school, as both groups of less and more graduated students showed similar responses. It seems therefore that acceptance of DCD donation goes beyond of education in our society. Wu et al. found a higher acceptance rate of DBD donation (69.7\%) than DCD donation (30.3\%) among students of traditional Chinese Medicine ${ }^{13}$, showing that the organ transplant education for medical students and the public is warranted. 


\section{CONCLUSIONS}

This study showed that medical students in Brazil are well informed about organ donation, particularly regarding donation after brain death, even though there is still room for improvement. However, there is a clear lack of information and consequently in acceptance of DCD. Education in the field of end-of-life management may improve not only the acceptance of DCD donation, but the whole understanding of planned withdrawal of life-sustaining therapy.

\section{ACKNOWLEDGMENTS}

We would like to thank the FAPESP (Fundação de Amparo à Pesquisa do Estado de São Paulo) for granting a scientific initiation scholarship for Diogo Visconti Guidotte (process number 17/24771-7).

\section{AUTHORS" CONTRIBUTIONS}

RBM: Conceptualization, Funding acquisition, Investigation, Methodology, Project administration, Writing - original draft. DVG: Funding acquisition, Investigation, Writing - original draft. DRW: Data curation, Methodology, Writing - original draft. AGS: Formal analysis, Resources. AJFC: Formal analysis, resources. RMA: Methodology, Writing - review and editing. LBH: Data curation, Investigation. FHG: Conceptualization, Writing - review and editing. LACDA: Supervision, Writing - review and editing.

\section{REFERENCES}

1. Kootstra G, Daemen JH, Oomen AP. Categories of non-heartbeating donors. Transplant Proc. 1995;27(5):2893-4. PMID: 7482956

2. Morrissey PE, Monaco AP. Donation after circulatory death: current practices, ongoing challenges, and potential improvements. Transplantation. 2014;97(3):258-64. https:// doi.org/10.1097/01.TP.0000437178.48174.db

3. Johnson RJ, Bradbury LL, Martin K, Neuberger J, UK Transplant Registry. Organ donation and transplantation in the UK-the last decade: a report from the UK national transplant registry. Transplantation. 2014;97 Suppl 1:S1-S27. https:// doi.org/10.1097/01.TP.0000438215.16737.68

4. Mirshekar-Syahkal B, Summers D, Bradbury LL, Aly M, Bardsley $\mathrm{V}$, Berry $\mathrm{M}$, et al. Local expansion of donation after circulatory death kidney transplant activity improves waitlisted outcomes and addresses inequities of access to transplantation. Am J Transplant. 2017;17(2):390-400. https://doi.org/10.1111/ ajt.13968

5. Dimensionamento dos transplantes no Brasil e em cada estado. Registro Brasileiro de Transplantes; 2018:XXIV(4). 2018. Available from: http://www.abto.org.br/abtov03/Upload/file/ RBT/2018/Lv_RBT-2018.pdf.

6. Galvao FH, Caires RA, Azevedo-Neto RS, Mory EK, Figueira ERR, Otsuzi TS, et al. Attitude and opinion of medical students about organ donation and transplantation. Rev Assoc Med Bras (1992). 2007;53(5):401-6. https://doi.org/10.1590/ s0104-42302007000500015

7. Chen JX, Zhang TM, Lim FL, Wu HC, Lei TF, Yeong PK, et al. Current knowledge and attitudes about organ donation and transplantation among Chinese university students.
Transplant Proc. 2006;38(9):2761-5. https://doi.org/10.1016/j. transproceed.2006.08.140

8. Dutra MMD, Bonfim TAS, Pereira IS, Figueiredo IC, Dutra AMD, Lopes AA. Knowledge about transplantation and attitudes toward organ donation: a survey among medical students in northeast Brazil. Transplant Proc. 2004;36(4):818-20. https:// doi.org/10.1016/j.transproceed.2004.03.066

9. Ríos A, López-Navas Al, López-López Al, Gómez FJ, Iriarte J, Herruzo $R$, et al. Acceptance of living liver donation among medical students: a multicenter stratified study from Spain. World J Gastroenterol. 2016;22(25):5800-13. https://doi. org/10.3748/wjg.v22.i25.5800

10. Xie JF, Wang CY, He GP, Ming YZ, Wan QQ, Liu J, et al. Attitude and impact factors toward organ transplantation and donation among transplantation nurses in China. Transplant Proc. 2017;49(6):122631. https://doi.org/10.1016/j.transproceed.2017.02.060

11. Rabiu TB, Oshola HA, Adebayo BO. Survey of the knowledge of brainstem death and attitude toward organ donation among relations of neurosurgical patients in Nigeria. Transplant Proc. 2016;48(6):1898-903. https://doi.org/10.1016/j. transproceed.2016.05.011

12. Stolz E, Großschädl F, Mayerl H, Rásky É, Freidl W. Determinants of acceptance of end-of-life interventions: a comparison between withdrawing life-prolonging treatment and euthanasia in Austria. BMC Med Ethics. 2015;16(1):81. https://doi. org/10.1186/s12910-015-0076-y

13. Wu X, Gao S, Guo Y. Attitude of students in Shanghai University of traditional chinese medicine toward donation after cardiac death. Transplant Proc. 2020;52(3):700-5. https:// doi.org/10.1016/j.transproceed.2019.12.036 